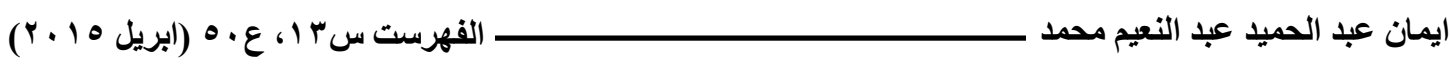

\title{
موسوعة النظرية الثقافية : المفاهيم والمصطلحات الأساسية
}

\author{
عرض وتقيبم \\ إيمان عبد الحميا عبد النعيم محمد وتئم \\ مدرس مساعد بقسم المكتبات و الوثائق وتقتية \\ المعلومات المات المات \\ كلية الآداب - جامعة القاهرة
}

إدجار، أندرو ؛ سيا جويك، بيتر

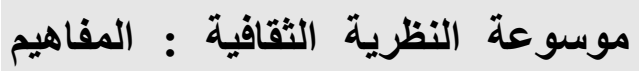

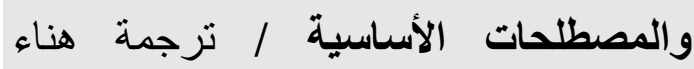
الجوهري ؛ مراجعة وتقديم وتعليق محمد الاسياسئ

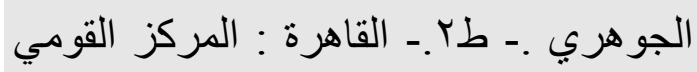

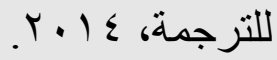

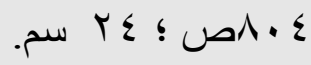

يُعد العمل - الذي نحن بصدده - بمثابـة

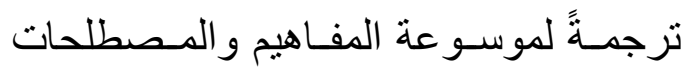

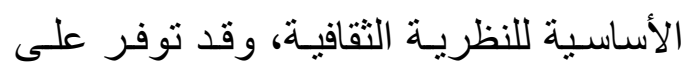

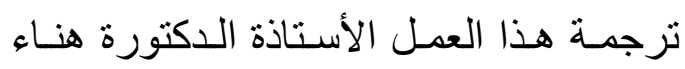

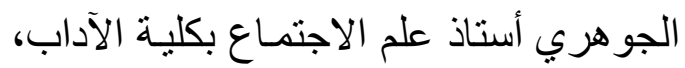

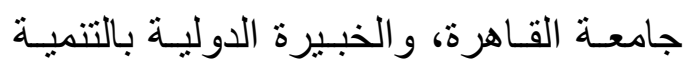

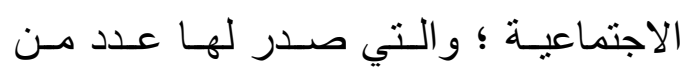

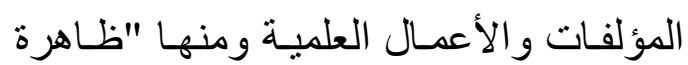
الأعمال الإضافية غير الرسمية بين موظفي

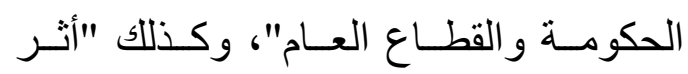

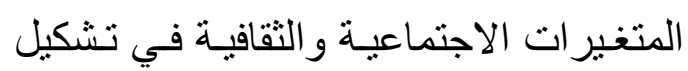
نوعية الحياة في المجتمع المصري"، وصدئ وصدر

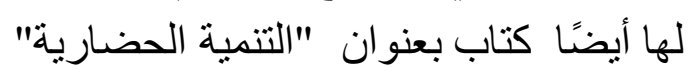

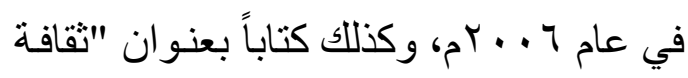

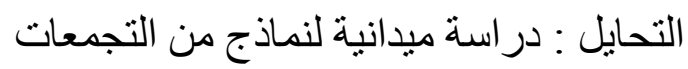

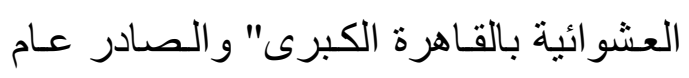

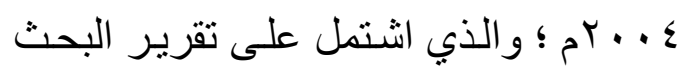

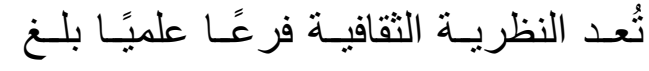

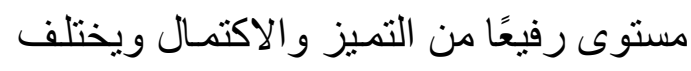

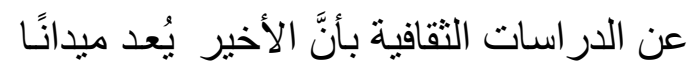

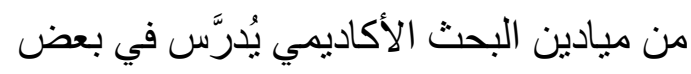

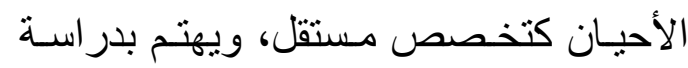

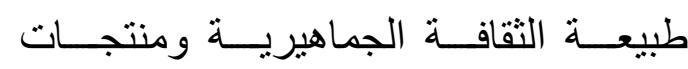

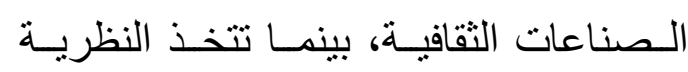
الثقافية من در اسة كافة جوانب الثقافة مجالاً

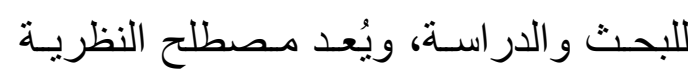

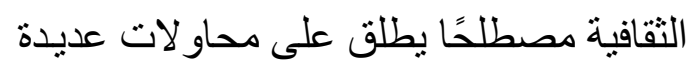

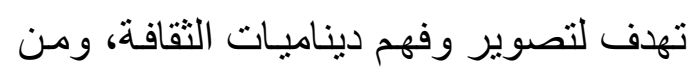
الناحيـة التاريخيـة يتضمن ذلك الجدل حول فئل

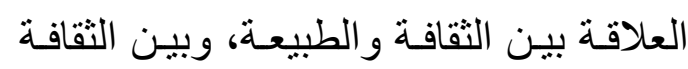
و المجتمـع وكذللك الفـارق بيـن الثقافـة العليـا و التقافة الدنيا، و التداخل بين التراث الثقافي

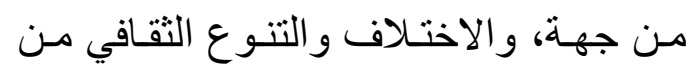

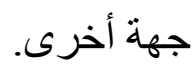


وتجــر الإثــارة إلـى أنَّ هــا العهـل العـل

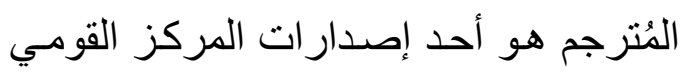
للترجمة ؛ و الذي تهدف إصدار اته إلى تقديم الاتجاهات و المذاهب الفكرية المختلفة للقارئ العربي وتعريفه بها.

يضم هذا المعجم الموسوعي المفاهيم

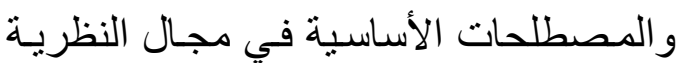
الثقافيـة وهي المسطلحات الأهـ و الأكثر تداو لاً في إطار النظريـة الثقافيـة المعاصرة،

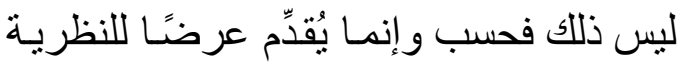
الثقافية يتميز بشمول الاتجاه قدر الإمكان و لا ينحاز لتوجها بعينه، ورُوعي فيهـ أن يتنـاول الأفكار التي لها صلة و اضحة بدر اسة الثقافة

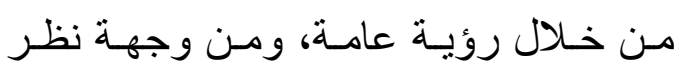

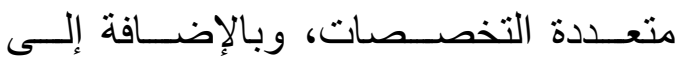
المـصطلحات و الدفـاهيم الرئيسـية الأكثر شـرة في مجال النظريـة الثقافية سعى هذا

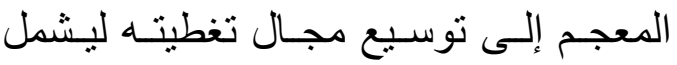
الأدوات المفاهيمية والثقافية التي توفر لهذه الأفكار أسسًا راسخة ودقة فكرية.

ويشتمل هذا المعجم على شرح وتفسير

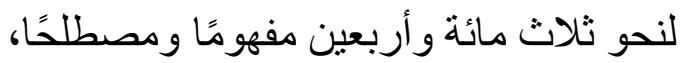

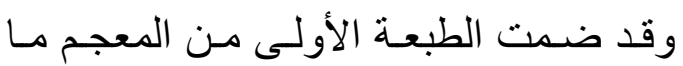

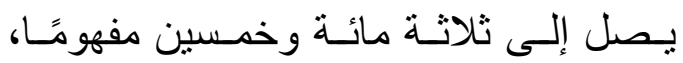

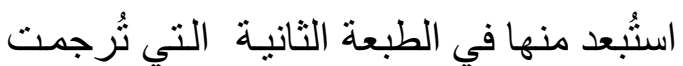

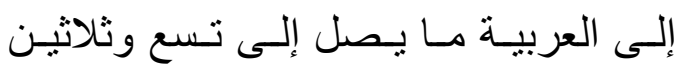
مصطلحًا، وكان القسم الأكبر من المداخل المستبعدة ينتمي إلى ميدان الفن وكذلك بعض الكض الك الك

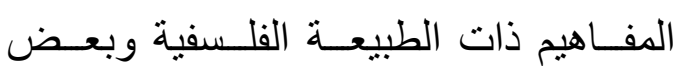

الـذي أعدتهـه في إطـار مـشروع "الـتراث

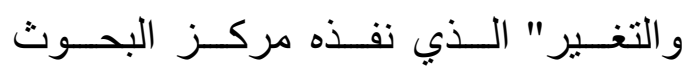

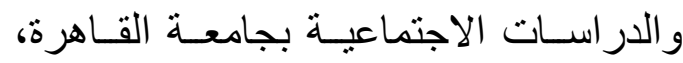
وبالإضـافة إلى ذلـك قامـت بإعداد دراسـة

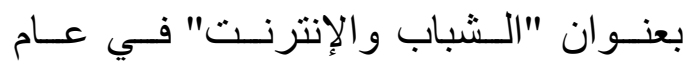

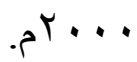

وقام بمر اجعة هذه العمل وتقديمه الأستاذ

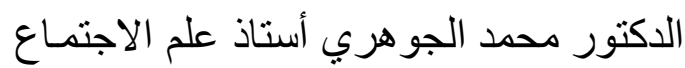
بجامعة القاهرة وعميد كلية الآداب ورئيس الإنيس

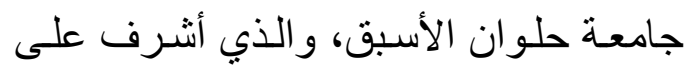
عددٍ كبير من البحوث وشارك كذلك في كثير الآن من الندو ات و المؤتمر ات الدولية واتية والعربية في

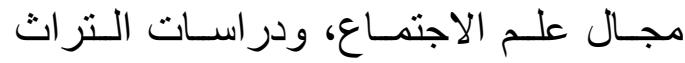

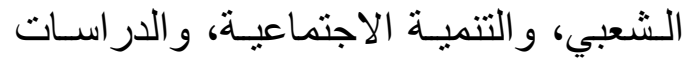

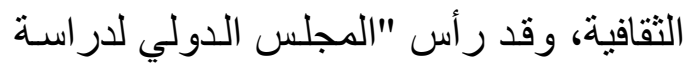

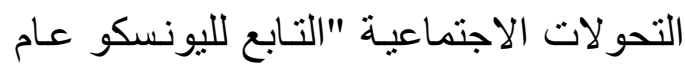
1990

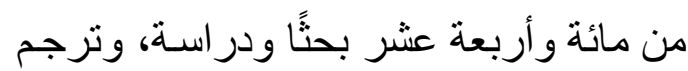
وشارك في ترجمة ما يصل إلى اثني وثناثين عملاً.

أمـا عن العمل الأصلي فقد توفر على العـ

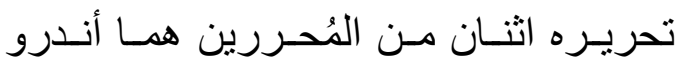

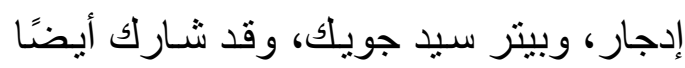
في تأليف هذه العمل جديون كالدر، ريتشارد

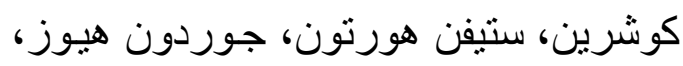

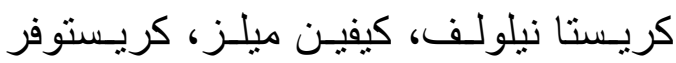

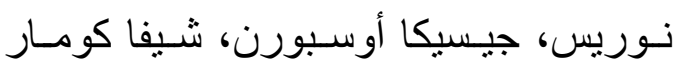
شرينيفانسان، روبن و اكربارت، وكريستوفر ريت. 
الأصلية ـ ترتيبًا هجائيًا، كذللك اتُّبعت نفس

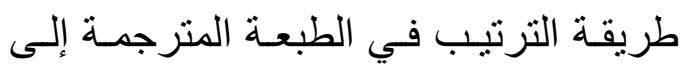

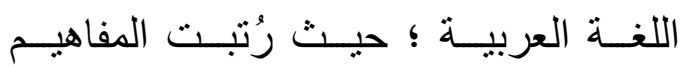

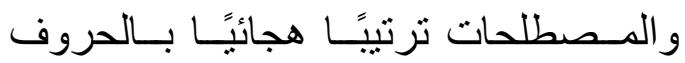

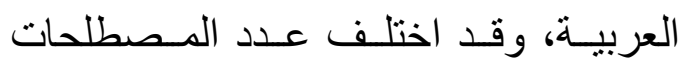
الواردة تحت كل حرف. ولخدمة القارئ الذي يعرف المُصطلح

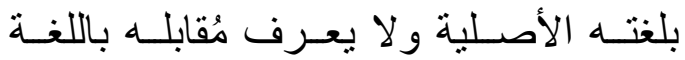

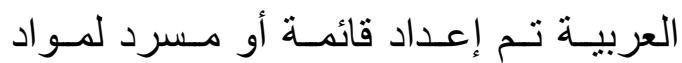

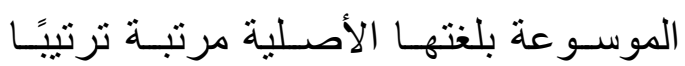

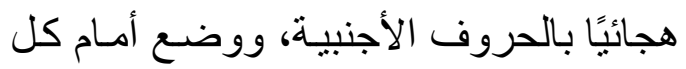

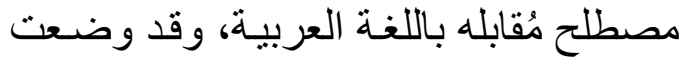

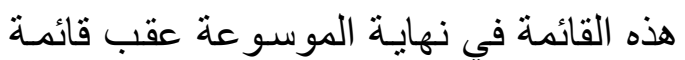

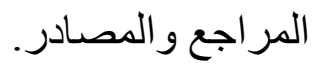

وتجدر الإشارة إلى أنَّ "ال" التعريف لم

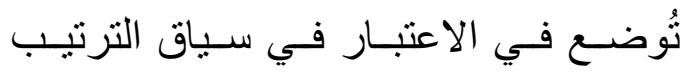
الهجـائي لمـو اد العمل،وقد اسـتخدمت إحالـة

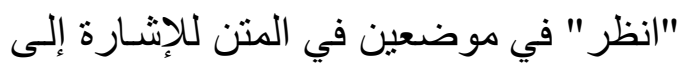

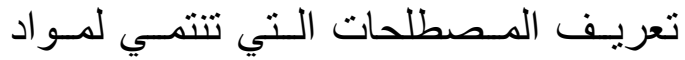
الموسـوعة وجـاءت ضـمن شـرح مـصطلح

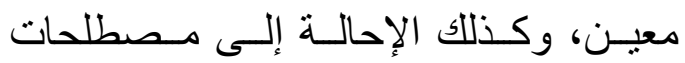

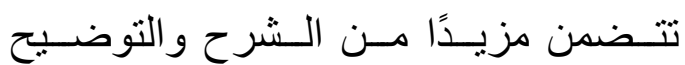

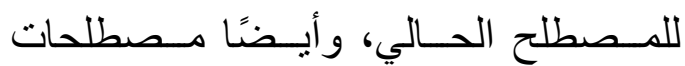

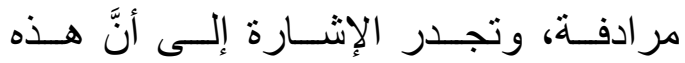

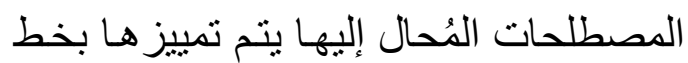
ثقيل. كذللك وردت إحالة انظر في الهامش السفلى للصفحة للإثـارة إلى تعريفٍ موجزٍ للمصطلح في هامش مادة أخرى. تسوق الموسوعة كل مصطلحٍ باللغةِ
المفـاهيم النفسية ،وكـذللك بعـض المفاهيـم اللغوية وبعض المفاهيم التقافية العامـة والتي بـي

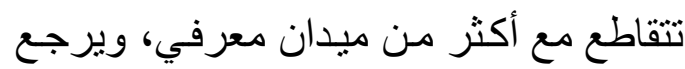
السبب في استبعاد هذه المصطلحات إلى أنَّ هن

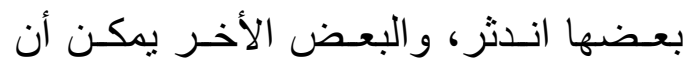
ينضم تحت مظلة فروع معرفية أخرى أكثر ولثر تخصـصاً كالمـصطلحات النفسية و الفلسفية

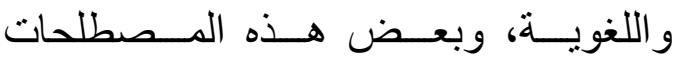
المستبعدة قد أصبحت من التراث المستقر في الثقافة الإنسانية المعاصرة ولم يُعد جزءًا من الز اد اليومسي للمشتغلين بالثقافـة، وكذلك تم استبعاد بعض مو اد اللغة ومصطلحات علوم الاتصـال لأنَّ هذه التخصـصـات العلميـة قد نمت و اتسعت وتطورت إلى الحد الذي يسمح باستبعاد تلك المصطلحات التي تنتمي إليها و إحلال مفاهيم أحدث و أكثر إثارة للجدل. وقـد تـم إضـافة مـا بـصل إلـى ســـ و عشرين مصطلحًا مُستحدثًا على هذه الطبعة الثانيـة التي تم ترجمتهـا إلى العربيـة، رأى مهده مؤلفي ومحرري المعجم الموسوعي إضـافتها

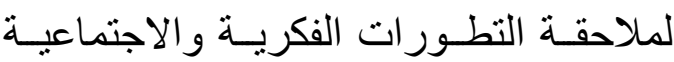
و السياســية والاقتــصـادية علــى الــصعيد العالمي، و أغلب هذه المصطلحات مـن ثمـار العولمة ومستجداتها، وكذلك تطور ات علميـة وهن

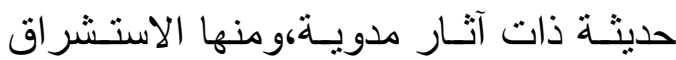

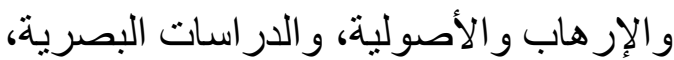
و علم الور اثذة وعلم تحسين النسل، و المواد ولاد المتصلة بفروع التكنولوجيا الحيوية. رُتبّبـت مـو اد هـذا العــل ـ فـي لغتهـا 
دلالة المصطلح، كنلك تم تمييز المصطلحات

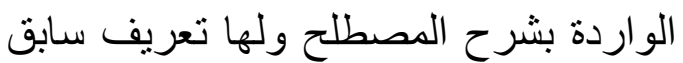
أو لاحق بالموسوعة ببنط طباعي ثقيل وبنفس حجم خط المتن. أما مسرد الدصطلحات فقد كان حجم الخط فيه أصغر قليلاً عن مثن الموسوعة نفسها ومُمِيّزت مداخلها أيضًا ببنط طباعي ثقيل.وقد تم استخدام الأقو اس لمزيد من التوضيح لبعض في لئل

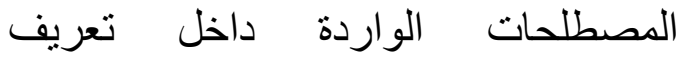
المصطلح ولم يتم إدراجها ضمن المفاهيم و المصطلحات الواردة بالموسو عة.

وقد جاء تجليد الموسوعة جيدًا إلى حد كبير، أما الخط فيتميز بالوضوح و الملائمة

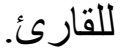

تجدر الإشارة إلى أن هذا العمل بمثابة معين للباحثين و الدارسين في مجالات عدة الإن

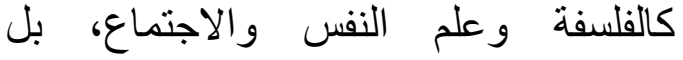
و المهتمين بالثقافة بوجٍٍ عام، وذلك من خلال

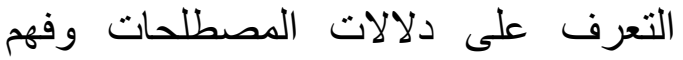
معانيها خاصة في ظل ما يتسم به من سهولة الأسلوب وبساطة العرض والتها فالتنظيم ويسر التعامل معهد و الإفادة بها.

ولا نغفل الإشارة أيضًا إلى أنَّ هذا العمل ليحقق الفائدة الكاملة للباحثين الباني والدارسين و المهتمين بحاجة إلى مزيد من الجهد لمتابعة استكمال و إضافة ما يستجد من التهن مصطلحات،ومحاولة التحديث و التصحيح

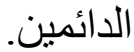

العربيةِ مع ذكر لمقابله بلغته الأصلية، وقد أورد المحررون تحت كل مصطلح شرئا

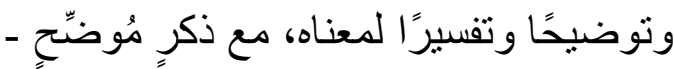
في كثير من الأحيان- للمعاني الأكثر

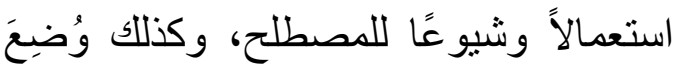

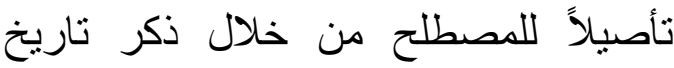

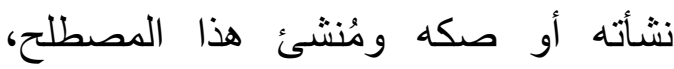
وكذلك المجال الذي يُستخدم فيه. ويذكر الدحررون أيضًا الأصل اللغوي لئه

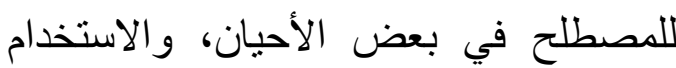
القديم للمصطلح وكذلك الاستخدام الحديث، مع التطورات التي طر أت على استخدامات المصطلح.

بالإضافة إلى ذلك يرد في هامش

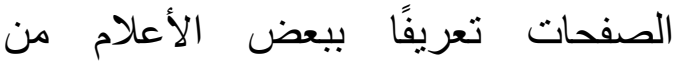

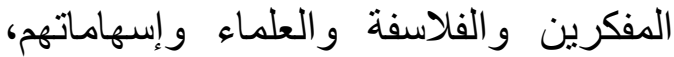
وقد تم التعريف بما يقرب من مائة وعشرين شخصية في سياق الموسو عة ككل. تم إخر اج هذا العمل في مجلد واحد من القطع المتوسط يضم ب. على الدفاهيم و المصطلحات وتعريفاتها، بالإضافة إلى قائمة المراجع و المصادر التي

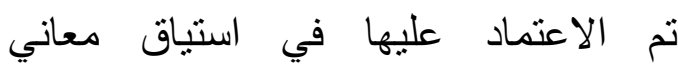
المصطلحات، يعقب للك مسرد بالمصطلحات الواردة بالموسوعة مرتبة ترتيبًا هجائًا وفقًا للهجائية الأجنبية وأمام كل مصطلح مقابله باللغة العربية. وقد تم تمييز

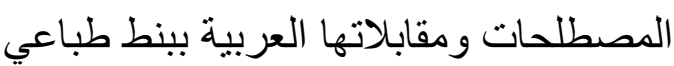
أسود ثقيل يكبر حجمًا عن شرح وتفسير 